\title{
A Critique of the Architecture of Faculty of Science Complex, University of Lagos, Nigeria
}

\author{
Adewale Segun Alabi* \\ Department of Architecture, Bells University of Technology, Ota, Nigeria, Km 8, Idiroko Road, Benja \\ Village, P.M.B. 1015, Ota, Ogun State, Nigeria
}

\begin{abstract}
Architectural criticism can be carried out using three distinct methods. These are descriptive, normative, and interpretive evaluations. Descriptive evaluation gives in-depth graphical and verbal expressions of pieces of architecture, thereby, ensuring in depth understanding of the work. The paper critiques the architecture of Faculty of Science Complex of the University of Lagos in order to provide intellectual and unbiased understanding of the design and architecture so as to make it a reference/study material which could influence future designs. It was built during the oil boom (1971-1977) by Godwin and Hopwood Architects. The complex can be classified as an international style, mostly related to modern architecture. This paper describes the building form, the building conditions, basic elements and sensory elements using the principles discussed in "Analyzing Architecture" by Simon Unwin. Findings reveal that a pleasing aesthetics of the design were achieved using the principles of orthodox modernism. However the present conditions of the building distorts the innovative façade of the building, thereby reducing the original science behind the orientation and elements of the building which were consciously applied in order to realise maximum energy savings and occupant comfort.
\end{abstract}

Keywords: criticism, architecture, faculty of science, University of Lagos

DOI: $10.7176 / \mathrm{ADS} / 77-07$

Publication date:October $31^{\text {st }} 2019$

\subsection{Introduction}

Quite a number of studies have been carried out on the art and science of architecture works. Studies on the science of buildings that have been carried out include post occupancy evaluations, indoor environment quality, material and technology innovations, and many others (Deuble \& John de Dear, 2012; Adwunmi, Onirin, M, Famuyiwa, \& O, 2011; Lee, Trcta, \& Hensen, 2011). Also, studies on the art of a building that have been done include aesthetics, concepts/philosophy, building ornamentation, metaphysics, criticisms (Leamington History Group, 2018; Longstreth, 2014; Gower, 2009; Cattermote, 2008; Thornton, 2006, Scruton, 1979), etc.

Buildings all over the world which have been analysed through criticism had attracted attention resulting in bountifully available information on these buildings. Examples are Swiss Re, United Kingdom; Burj Khalifa, Dubai; Falling Waters, USA; Burj Al Arab, Dubai; Sydney Opera House, Australia; Villa Savoy, France; Villa Venturi, USA; Trump Towers, USA; CCTV Headquarters, China. A closer look reveals that most of such works of architecture are located in places with totally different climatic characteristics from Nigeria but are still studied nonetheless as design references.

There are many buildings in Nigeria (either designed by Nigerian architects or foreign architects) which by all standards could have attracted the same or similar interest but which have been put under critical lenses of review. Such buildings include the national theater, Iganmu, Lagos, Cocoa House, Ibadan, Civic centre, Victoria Island, Lagos, Senate House, University of Lagos etc. This aims of this study therefore to draw attention to an architecture of faculty of science complex, University of Lagos in order to bring about a better understanding of its workings so as to make it a design reference for tropical climate. To achieve this, descriptive analysis will be used from the philosophical standpoint of architectural criticism.

\subsection{Background}

In the 70's during the era of oil boom in Nigeria, the Federal Government embarked on various construction projects quite a number of which were Educational Institutions (Arayela, 2001). The University of Lagos had many of its prestigious structures designed and built in this era. Most architects used were foreigners who brought their international style characterised by modernism and adapted it to fit the climatic situation of Southwest Nigeria. The Faculty of Science Complex is one of those structures which was designed using the principles of modernism but was adapted to respond to the climatic characteristics of the environment so as to be habitable and comfortable.

The faculty has been in use since its completion in the late 70's and in response to increasing demands/populations, different alterations and amendments have been made. This study takes a logical approach to describe in words and images complex's orientation, materials, layout and expected performance as well as taking note of the changes experienced by the building and its implications. It is hoped that this critique will create a platform for better understanding of the architecture of the science complex in order to provide a 
knowledge base for future designs which would respond positively to the climatic conditions of Southwest Nigeria.

\subsection{Method}

In order to carry out this study on the Faculty of Science Complex, architectural criticism was used as the philosophical standpoint. This is because there is a need to perceive the physical phenomena of the building in accordance with the feelings generated through written and graphical representations so as to establish an experience and in depth understanding of that building (Bonta, 1979).

According to Attoe, (1978) there are three distinct groups used in critical evaluation process in art and architecture, which can be subdivided into ten methods. First is the descriptive evaluation which can be depictive, contextual, or biographical. Second is the normative evaluation which can be typal, measured, systematic, or doctrinal. Third is the interpretive evaluation which can be evocatory, advocatory, or impressionistic. The method of evaluation employed in this study is the descriptive evaluation that is depictive in nature. Thus observations gave birth to verbal and graphical depictions which are not judgmental but logical in nature (Attoe, 1978). The process used to carry out these depictions is based on guidelines used by Unwin, 2007.

\subsection{Findings}

Built in the '70s, during the era of oil boom (1971-1977) in Nigeria (Godwin \& Hopwood, 2012), the Faculty of Science complex of the University of Lagos is characterized mainly by concrete elements used as the core building envelope consisting of flooring, walling and roofing. The building was designed by Godwin and Hopwood Architects, a well-known British firm operational in Nigeria (Godwin \& Hopwood, 2012).

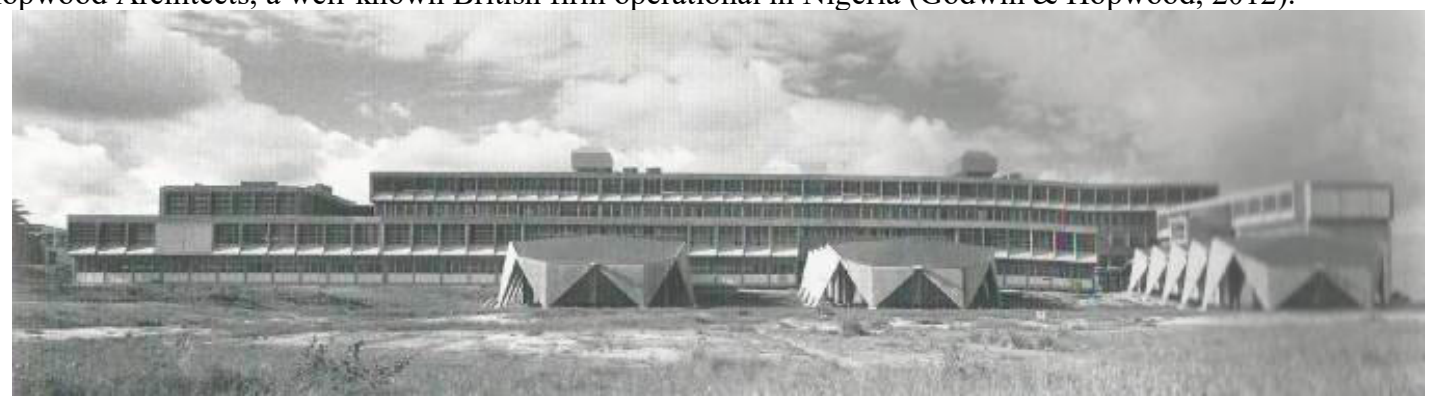

Figure1: View of the just completed faculty of Science complex from the Lagoon (Source: Godwin \& Hopwood, 2012)

The complex can be classified as an international style, mostly related to modern architecture which was a fashion and norm at that period especially in most federal institution of learning in the country. The science block is located towards the eastern end of the campus at the edge of the lagoon. A dense grove of trees covers the longitudinal approach from the north view, making the building a mystery to be solved as just a glimpse of the building is seen. The peek seen through the trees gives an instant impression of an iconic building. Within full view, the structure is unique, easily recognizable and simple, a gem located out of sight!

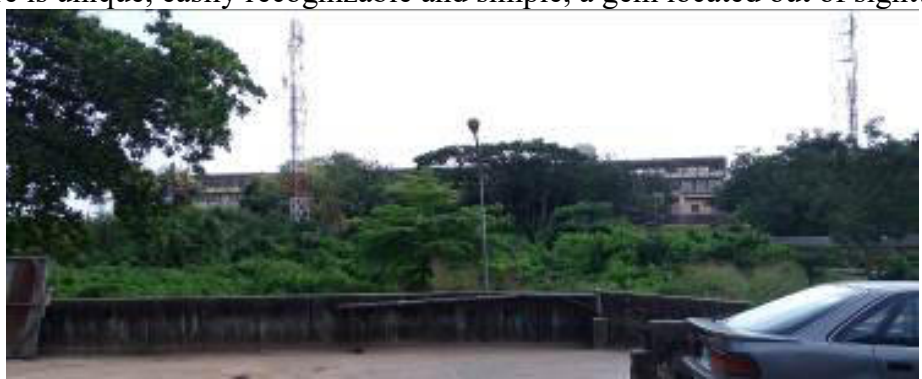

Plate 1: North approach view (Source: Author, 2016)

The main entrance is situated at the mid-section of the longitudinal north elevation, although not pronounced, it is raised to allow free flow of air within the building synonymous to Le Corbusier's approach to modern architecture permitting stack effect. Promoted as new architecture, Le Corbusier described it in his book "Vers Une Architecture" published 1923, translated as Towards a New Architecture (1927), in which he celebrated amongst other things the beauty and adventure associated with ocean going liners (Le-Corbusier, 1923). 


\subsection{Layout and Identification of place}

The land has a dramatic slope from north and west down to the south and east towards the lagoon. The south west gives the most impact of wind from the Atlantic Ocean. The longer sides of the buildings are positioned to face North-South to reduce the sun shading of the structure, in order to reduce energy load of the structure (Reza \& Mohammadjavad, 2015). However, admirable as the architecture may be, reduced energy load due to orientation may, arguably, be less achievable due to the massive concrete forms.

The layout of the science block consists of two longitudinal buildings, one to the north and the other to the south, and three polygonal buildings arranged along the south side of the block. The north accommodates the administrative section and the southern block contains the laboratories and classrooms which link the three polygonal shaped lecture theatres. The north and south blocks are connected with walkways perpendicularly attached by link bridges and stairs (for vertical movement) at each end; between the blocks and separated by the connecting walkways are courtyard gardens and concrete retaining walls with perforations having a basket weave appearance. These perforations permit absorption of water by the soil and growing pockets of grass encouraging natural means of preventing erosion, reducing surface runoff, glare and heat build-up.

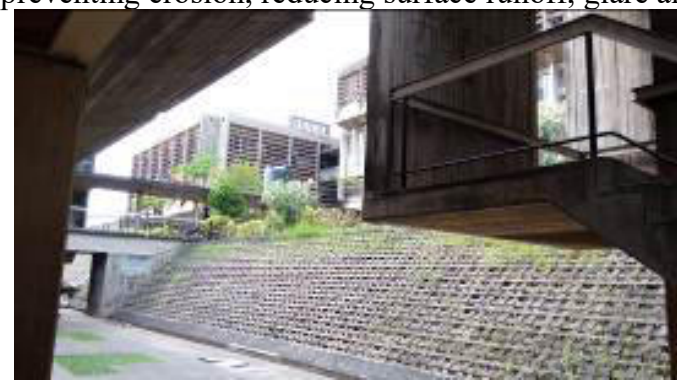

Plate 2: Concrete retaining walls with basket weave appearance perforations (Source: Author, 2016)

The retaining walls serve a great function in holding up the sloping terrain towards the south and also serve as the basement floor. The gardens create good scenery for passersby. The natural landscape considered in the design of the retaining walls cushions the hardness imposed by the massive concrete of the building. However, over time, the original intention of keeping the gardens within the courtyard area green has somewhat been encroached upon with the unguided intrusion of some services such as indiscriminately installed pipes and water tanks.

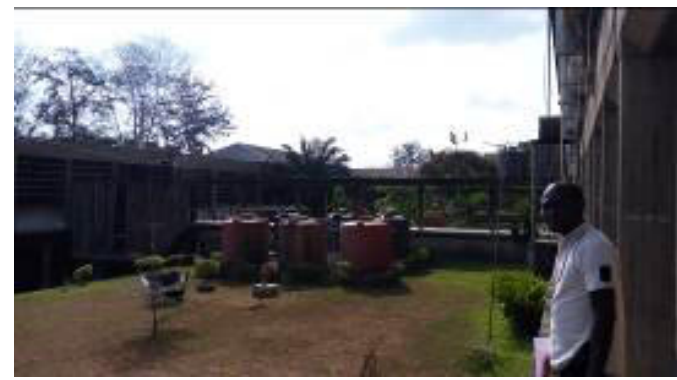

Plate 3: Courtyard area encroached upon with unguided intrusion of some services (Source: Author,2016)

\subsection{Building Conditions \\ 4.2.1 Flat roof}

The flat roof is synonymous with modern architecture design which was in vogue in the 1970's. This flat roof system failed due to various reasons but majorly the lack of maintenance which allowed water to seep into the concrete roof surfaces.

\subsubsection{Ventilation}

The design was intended to make maximum use of ventilation in order to have an adequate micro-climate by applying good orientation of the structure and the introduction of sun shading devices which would also act as funnels guiding air into the structure. It appears that this was not fully achievable because of the presence of air conditioners dotting the structure in an obviously unplanned arrangement. These ACs are fitted into any conceivable available space such as the roof and windows. The need for these mechanical coolants is probably due to the ability of concrete to absorb and conduct heat in large quantities thus making rooms hot despite constant flow of natural air. The interior spaces had been originally insulated with the use of wood panels which 
over time were stripped away and replaced with PVC panels which do nothing about insulation. Small wonder, the heat gain of the building required a mechanical solution.

Conversely, the installations were not properly and neatly carried out, which now gives the façade of the building a deformed look especially where outlets have been drilled on the parapet walls and units mounted on windows and wall surfaces in an unsynchronized manner.

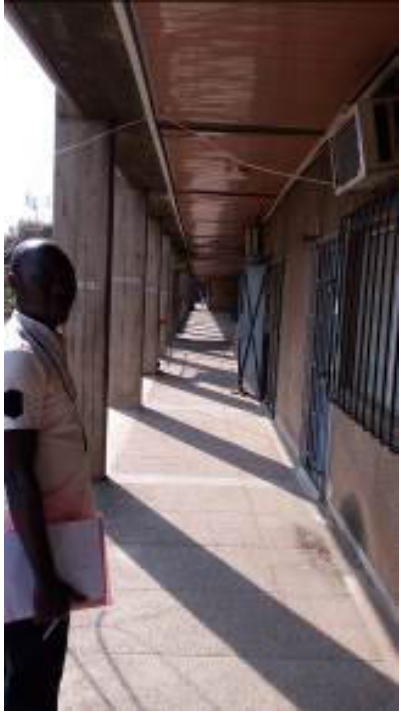

Plate 4: ceiling replaced with PVC panels (Source: Author, 2016)

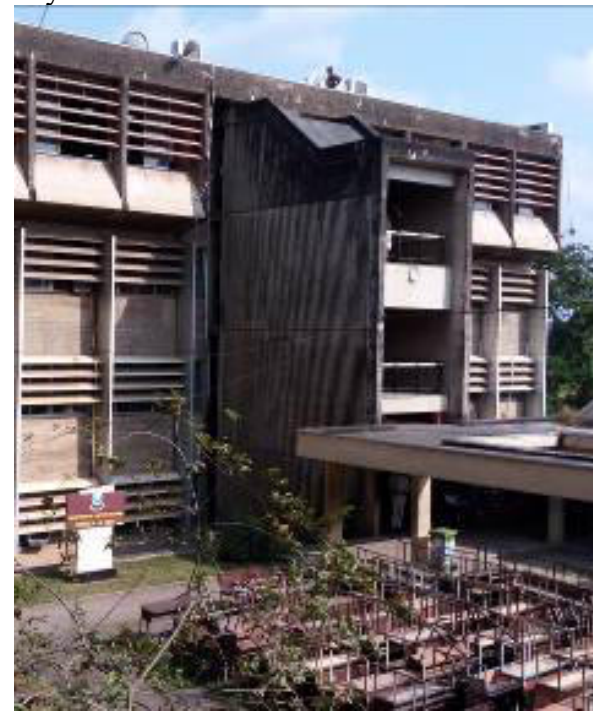

Plate 5: Drilled parapet walls for AC piping (Source: Author, 2016)

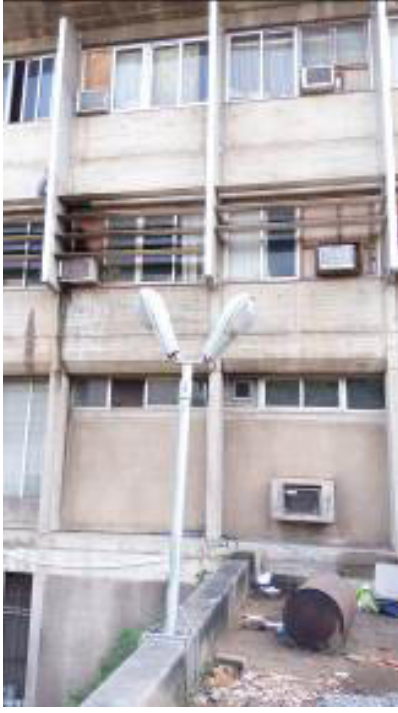

Plate 6: Units mounted on windows and walls in a haphazard fashion (Source: Author, 2016)

\subsubsection{Finishes}

The neatness of the structure in terms of it finishes is commendable despite the fact that they are mainly concrete finished. The cladding of the ceiling is made of wood this is observed in the walkways, lobbies and the reception area which gives a welcoming and comforting effect. Newer modifications to the ceiling cladding is the replacement of the wood cladding with PVC cladding especially at upper levels. This was also carried out neatly and gives a feeling of newness.

\subsection{Basic Elements}

The principal architectural elements employed are the concrete walls, columns, beams, floors and the glass windows and wooden ceiling. Other basic elements used are the path, the main entrance only defined from the longitudinal north view, consists of car park, three staircases and between the first two staircases, the reception which leads to the lobby walkways and courtyards. Also the circulation is such that there are covered links between the two main buildings with the courtyards defining the portions between the links.

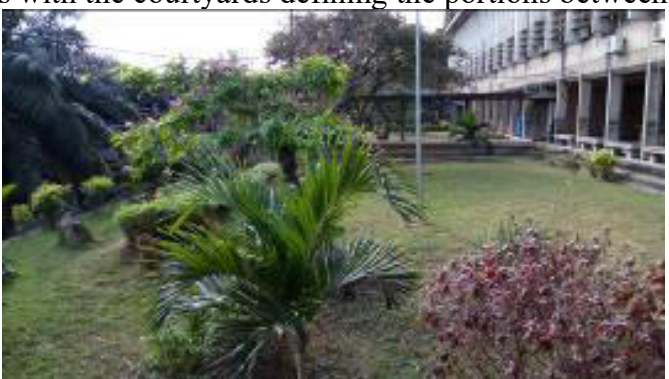

Plate 7: Courtyard Garden, defining the portions between the links (source: author, 2016)

\subsection{Sensory elements}

Predominantly a fair-faced concrete finish, there is a great play with some architectural sensory elements which bring forth emotions pertaining to the building's appearance. This was achieved with the inclusion of materials such as aluminum composite, steel, wood, stone and glass. 
"The first principle of architectural beauty is that the essential lines of a construction be determined by a perfect appropriateness to its use."- Gustave Eiffel, 1887

The most important sensory element in the science complex is line. The structure is dominant with an array of vertical lines fitted with bursts of horizontal lines. In architecture, lines are often suggested by the structural material which designers choose for their buildings. Messrs Godwin and Hopwood chose to break the horizontality of the complex structure using arrays of bold vertical fins though intersected at the uppermost floor, this gives the impression of a 'fast moving train'. The pronounced vertical lines of fins running at intervals across the band of the structure between the first and the second floor, cut off from the ground floor but continues after the cantilever on the third floor. Apart from the vertical fins are the groups of four and five floor horizontal slats fitted over all lower and uppermost windows. The vertical fins breaking the horizontality of the structure together with the slats create a nice interplay on the exterior façade and serve as sun breakers.

4.4.2 Shape

The structure construes a rectilinear shape, either from its surfaces or from the composition of spaces. This is evident in elements like fins, columns, walls, windows, and doors. Outstanding too is the composition of triangles to form polygonal shape unmistakable seen in the three folded plate structures which accommodate lecture theatres.

\subsubsection{Colour}

The building was left in its raw concrete colour, a fair face concrete which greatly reduces the cost of maintaining the exterior building due to cost of painting. This grey look gives the building a soft feel which blends with the surrounding green.

\subsubsection{Texture}

The floor is rendered as a rough surface and patterned in a mixture of square and rectangular staggered recesses with smooth rendering. Also the smooth rendering extends from each rectangular column on the floors. The cladding of the ceiling are strip patterns made from wood replaced in some places with PVC strips.

4.4.5 Geometry

One of the most obvious characteristics of the complex is the orthodox modernism. "The distinctive palette of elements used by orthodox Modernist architects included: the flat roof; emphasis (externally) of the horizontal floor; the column (piloti), allowing the opening up of the ground level and 'free planning'; and the glass wall, which reduced (visually) the cellular division of space internally and between inside and outside" (Gartman, 2010; Gartman, 2000).

The ideology of making the building a focal point is not given the highest priority, however an attraction is the way polygonal shapes are allowed to distort the view of the regular cuboid shape. This is observed on the south elevation viewed from the lagoon. The two water tanks on the roof top, act as storage space and act as markers. Also, the polygonal shaped lecture theatres attached to the laboratory area with unique folded plates as roofing stand out from the rest of the structures.

\subsection{Space organization and Structure}

Space is one of the most important considerations an architect must think about while designing a building. The design expressed the use of orthogonal organization of spaces into places. Space is the relative position of one three-dimensional object to another.

The structure of the complex is a skeleton of concrete frame. Its columns are laid out on a regular grid, but respond to the complex attitude of four cuboids and three polygonal forms in order of two, three, and four floors. The entrance cuboid (north elevation) has four floors, the south elevation cuboid has two floors, west end and the east end cuboid (rear view) both have three floors, and attached to the laboratory are three polygonal shaped structures.

\subsection{Using things that are there}

The designer used the view to the south to help in the organization of his plan. But most probably the effective thing he used that was already there was the slope of the land. The effect of this is most apparent at the upper and lower ground levels which accommodate the laboratory and the lecture theatres. The slope allowed main entrance into the complex not at the lowest, rather like entering a modern train/subway station.

\subsection{Architecture as making frames}

The science complex emphasizes the horizontality of the structure with its division into three pronounced horizontal levels which relate to the surrounding landscape. It does not enclose the occupant in a protective shell; its platforms and roof protect them from the sky, but the sides are open to the horizon. And its allusion to train and movement seems to suggest that the structure is a vessel rather than arrays of cubicle. 


\subsection{Conclusion}

Pleasing aesthetics of the design were achieved using the principles of orthodox modernism. The science behind the orientation and elements of the building were consciously applied in order to realise maximum energy savings and occupant comfort. However, distortions to the innovative façade have invariably affected the original energy saving gains.

\section{References}

Adwunmi, Y., Onirin, M, Famuyiwa, F., \& O, F. (2011). Post-occupancy Evaluation of Postgraduate Hostel Facilities. Facilities, 148-168.

Arayela, O. (2001). An Introspection into Forty Years of Architectural Practice in Nigeria (1960-2000). In U. O. Nkwogu, The Way Forward (pp. 91-107). Akure: Shalom Publishers.

Attoe, W. (1978). Architecture and Criticism. New York: John Wiley \& Sons.

Bonta, J. P. (1979). Architecture and Its Interpretation. New York: International Publications Inc.

Cattermote, P. (2008). Architectural Excellence: 500 Iconic Buildings. Firefly Books Ltd.

Deuble, M. P., \& John de Dear, R. (2012). Green Occupants for Green Buildings: The Missing Link? Building and Environment, 21-27.

Gartman, D. (2000). Why modern architecture arose in Europe, not America: The new class and the aesthetics of technocracy. Theory, Culture and Society, 75-96.

Gartman, D. (2010). "Economy and field in the rise of postmodern architecture" In Theorizing the Dynamics of Social Processes. Current Perspectives in Social Theory, 343-374.

Godwin, J., \& Hopwood, G. (2012). Sanad City: Lagos at 150. Lagos: Kachifo Ltd.

Gower, M. (2009). Cool Buildings. Oxford: Oxford University Press.

Leamington History Group. (2018). Royal Leamington Spa. Leamington: Leamington History Group.

Le-Corbusier. (1923). Vers une Architecture, trans. F. Etchells (1927) Towards a New Architecture. London: John Rodker.

Lee, B., Trcta, M., \& Hensen, J. L. (2011). Embodied Energy of Building Materials and Green Building Rating Systems - A Case Study for Industrial Halls. Sustainable Cities and Society, 67-71.

Longstreth, R. (2014). Frank Llord Wright: Preservation, Design and Adding to Iconic Buildings. Virginia: University of Virginia Press.

Reza, M., \& Mohammadjavad, F. (2015). "Optimisation of building shape and orientation for better energy efficient architecture". International Journal of Energy Sector Management, Vol. 9 Iss 4 pp., 593 - 618.

Thornton, R. (2006). Victorial Buildings of Birmingham. Birmingham: Sutton Publishing.

Unwin, S. (2007). Analysing Architecture. . London: Routledge. 